\title{
What Transaction Costs are Acceptable in Life Insurance Products from the Policyholders' Viewpoint?
}

\begin{abstract}
In this paper, we consider two life insurance contracts, a mutual fund and a risk-free investment, as alternative investment forms. The first two products under scrutiny are a life insurance investment with a point-to-point capital guarantee and a classical participating contract with an annual (cliquetstyle) interest rate guarantee and participation in the insurer's surplus. We posit that the three risky investments are based on the same stochastic underlying that can be modeled by a geometric Brownian motion. For the life insurance products, we focus only on the savings part and assume that they are priced in a risk-adequate manner for a given upfront payment. We consider the possible transaction costs to be carried by the policyholders. The policyholder assesses the various investment opportunities (life insurance products, mutual funds, risk-free investments) using different financial performance and utility measures. For selected types of risk profiles, we assess the utility position and the investor's preference for the various investments. Based on this analysis, we study which cost levels can make all of the products equally rewarding for the investor (assuming that each investment yields the same utility). Our findings indicate that insurance providers need to be very careful about the costs that their products impose on the targeted policyholder groups.
\end{abstract}

Key words life insurance products $\cdot$ financial guarantees $\cdot$ utility measure $\cdot$ transaction costs 


\section{Introduction}

Transaction costs such as distribution costs, administration costs and management depot fees lower the overall performance of an investment product from the buyer's perspective. Over the last few years, the discussion about the amount and adequacy of transaction costs in investment products in general and life insurance products in particular has intensified. For many reasons, it is not easy to answer the question of whether an investment in a life insurance product is beneficial for the investor compared to the alternatives (e.g., mutual funds): life insurance products typically contain a term life component and a savings component. In general, the investor needs either to know the portion of the premium payments that are reserved for the savings component of the product or to request information about the fair or market price of the term life insurance component. In addition, the amount of transaction costs and how they are distributed via the two product components is typically not fully transparent, although current efforts by regulators and consumer protection agencies require insurance companies to provide more information to their customers in this respect (see, e.g., the new European Union Insurance Distribution Directive). Furthermore, various risk and return figures are underlying the alternatives, and the market may not be completely efficient. More precisely, even within a particular risk class, there may be products that show over- or underperformance within a given investment horizon. Compared to typical mutual funds, the savings component of a life insurance product often contains specific forms of investment guarantees that need to be evaluated by the investor to make a comprehensive comparison between different alternatives. The current low-interest-rate environment and volatile asset markets make it a challenge for insurers to fulfill the promised investment guarantees (see, e.g., Schmeiser and Wagner, 2015 or the recent studies by Swiss Re, 2014, 2015). More specifically, decreasing interest rates ceteris paribus increase the guarantee's fair value. If the customer's willingness to pay for the insurance contract is not influenced by decreasing interest rates, the insurer's ability to pass on transaction costs to the customer may be substantially reduced. In our analysis, we find that, depending on the product guarantees, on the investment and on the risk aversion of the customer, double digit percentages up to $30 \%$ of the investment amount are acceptable for transaction costs.

In this paper, we would like to address the following question: Given a risk-free investment opportunity, what transaction costs for life insurance products (savings component) would be acceptable from the customer's point of view? In order to get a firm conclusion to this question, we provide a valuation (in the sense of a "fair" pricing) of various investment opportunities, including two forms of embedded guarantees, in a Black and Scholes modeling environment without taking transaction costs into account and compare that valuation to the policyholder's willingness to pay using two forms of utility functions and applying various degrees of risk aversion. The two forms of embedded options presented in our paper are the most common forms: a point-to-point and a cliquet-style guarantee. We interpret the discrepancies between the two pricing forms as a potential loading to cover transaction costs in a broad sense. More precisely, this loading may be used not only for transaction costs in a narrow sense (distribution costs, administration costs and management fees) but also to account for the insurer's model and parameter risks. Within various settings, we estimate the maximum level of transaction costs (in terms of the broad understanding that is described) in the different investment forms observed such that 
these investment opportunities are not worse than the risk-free investment. For all investment forms, we consider underlying funds calibrated on life insurers' average asset allocation in Germany (a mix of government bonds, stocks, real estate, hedge funds and money market) and use time series data to derive the input parameter for the underlying dynamic. This fund structure is used for all risky investment forms. In addition to different numerical examples and a sensitivity analysis, we provide a comparison between the maximum levels of transaction costs given by the theoretical model and the information available about the transaction costs charged to investors in the German market.

To the best of our knowledge, our research question - i.e., which transaction costs for life insurance products would be acceptable from the customer's point of view - has not been studied in the above-described context. Donnelly et al. (2014) address cost transparency in the life annuity market by decomposing products into components with individual prices. When guaranteeing actuarial fairness, mortality gains, investments returns and costs can be separated. Considering the fields of pension products Guillén et al. (2013) benchmark different strategies and find that the considered products are often outperformed by alternative products. Using a risk-adjusted utility approach, Guillén et al. (2014) and Kronborg and Jarner (2015) analyze the impact of administrative and investment costs linked to investments in a Black-Scholes financial market.

Based on our general assumptions about life insurance providers and purchasers' valuation techniques, we base our reasoning on the model setup provided in Gatzert et al. (2012). In this article, the authors focus on participating life insurance contracts and identify fair contract parameters (guaranteed interest rate, annual surplus participation rate, and terminal surplus participation rate) that maximize policyholder utility. Fair contract parameters are derived using a risk-neutral valuation that leads to a risk-adequate return for the equity holders (i.e., a net present value of zero) for all cases observed. Policyholders are assumed both to maximize expected utility and to have mean-variance state-dependent preferences. The two underlying valuation techniques - risk-neutral valuation and utility measurement have been widely used in the insurance literature. With respect to the valuation of insurance contracts, we are particularly interested in the work of Briys and de Varenne (1997), Grosen and Jorgensen (2002), Bacinello (2003), Ballotta et al. (2006), Gatzert (2008), and Schmeiser and Wagner (2011); these articles use option pricing theory to provide a "fair" valuation for various research objectives. With respect to the use of utility theory, the extensive literature on the demand for insurance is of particular importance. For instance, Berketi (1999) assumes mean-variance preferences to optimize a life insurance company's risk management activity from the policyholders' point of view. In Raviv (1979), the form of a Pareto optimal insurance contract is identified under general assumptions with respect to the risk preference of the insurer and the policyholder. Døskeland and Nordahl (2008) analyze how life contracts with return guarantees can be optimized to increase customers' welfare. The loss in returns caused by interest rate guarantees is discussed in Guillén et al. (2012). In addition, a great deal of research has analyzed an optimal insurance demand for corporate entities (cf., e.g., Mayers and Smith, 1982; Doherty and Richter, 2002; Doherty and Tinic, 1981). In addition to individual preferences, the demand for insurance depends on one's personal economic situation (Mayers and Smith, 1983) and the existence of alternative risk management instruments (see Ehrlich and Becker, 1972, for an analysis of the interrelations between insurance demand, self-insurance and self-protection). 
In addition to the paper by Gatzert et al. (2012), our paper has a connection to the recently published article by Schmeiser and Wagner (2015). The authors assess the optimal interest-rate guarantee level from the policyholders' viewpoint by using a power (isoelastic) utility function. Another related paper is that of Gatzert and Schmeiser (2009), which compares the pay-off structure for the savings component of unit-linked insurance products to embedded options for various forms of performance measures. More precisely, those authors focus on two forms of embedded investment guarantees: an interest-rate guarantee versus a look-back guarantee form. Finally, Eling and Holder (2013) analyze the interest-rate guarantee in German participating life insurance contracts and discuss alternative product designs in various economic environments from the viewpoint of an investor. It can be noted that participating life insurance contracts with interesting rate guarantees are still very common products in Central Europe. In some countries like Germany, Austria, Italy, and Switzerland - this product form is the bestselling product form in the market. ${ }^{1}$ Within the product group of participating life insurance products, we find differences in the way the investment guarantee is embedded (point-to-point guarantees versus cliquet-style form) and in respect to the used bonus distribution mechanism. For the bonus distribution mechanism regulatory requirement exists. An overview of typically participating contract forms including the modeling of embedded options and surplus participation for the Danish, German, British, Swiss, and Italian life insurance market can be found in Zemp (2011).

The paper is organized as follows. In Section 2, general assumptions regarding the model setup are presented. More specifically, the various valuation procedures of investment product providers and sellers are outlined, and we derive the input data for various asset classes. The empirical data and the model framework of Section 2 lay the groundwork for the numerical analysis provided in Section 3. In a reference setup, we will calculate the amount of transaction costs for various investment forms that are (at most) acceptable from the customer's point of view. In a sensitivity analysis, we observe how the customer's willingness to pay for transaction costs changes under different variations related to the input parameter, the utility function used, and the level of the investor's risk aversion. Finally, we compare the maximum level of transaction costs given by the theoretical model with transaction costs that we observe in the German insurance and mutual funds market. The main findings are summarized in Section 4.

\section{Model Framework}

\subsection{General assumptions and overview}

Premium payments in an endowment life insurance policy can typically be split into two components: a premium for term life insurance covering mortality risk, and a savings premium that is credited to the policy assets. Below, we focus on the savings premium only. This assumption simplifies the valuation procedure because we do not take into account early surrender, the premium paid-up option or deaths in the contract's duration. Thus, indemnity payments to the policyholder are only made at the contract's maturity. ${ }^{2}$ Under this assumption, the valuation can be performed using state-dependent preferences

\footnotetext{
${ }^{1}$ For a market overview cf. www.insuranceeurope.eu/insurancedata.

${ }^{2}$ This simplification in the context of the measurement of the asset performance of life insurance products is quite common in the relevant literature. See, e.g., Gatzert and Schmeiser (2009) and the cited primary sources in that paper.
} 
only. In addition, no conventions are needed with respect to the utility of the investor's bequest.

As in Schluetter (2014) and Gatzert et al. (2012), we assume that the insurer has access to the financial market and can replicate future cash flows via assets traded on the financial market. Buyers of the investment and the insurance product are unable to replicate future cash flows (at least not to the same extent) and cannot hedge their risks costlessly by using financial market instruments. Thus, buyers and sellers use different techniques to evaluate future payoffs. ${ }^{3}$ Under these assumptions, the existence of financial intermediaries can be explained, which would not be the case under a pure neoclassical model setup with perfect replication possibilities of future cash flows for all market participants. ${ }^{4}$

\subsection{Investment possibilities and costs}

Let $P_{0}^{\text {gross }}$ denote the investment amount (the savings premium in the case of the insurance product) of the investor. Thereby, the superscript "gross" stands for "before transaction costs" (see also Figure 1). Four different investment forms are examined. They are labeled with $i \in\left\{\mathrm{pp}, \mathrm{cs}, \mathrm{fi}, r_{\mathrm{f}}\right\}$ as follows:

- A life insurance product with a point-to-point guarantee on the investment amount (labeled $i=\mathrm{pp}$ );

- a participating life insurance product with a cliquet-style guarantee and policyholder participation in the asset returns (labeled $i=\mathrm{cs}$ );

- a mutual investment fund (labeled $i=\mathrm{fi}) ;^{5}$ and

- a risk-free investment (labeled $i=r_{\mathrm{f}}$ ).

Below, we consider the present value of the transaction cost ratio $C_{0}^{i}$ (this excludes guarantee costs, which are considered separately; see Section 2.4) at $t=0$. The transaction cost ratio of the investment form $i$ is defined as the present value of the absolute amount of transaction costs for $i$ in $t=0$ divided by $P_{0}^{\text {gross }}$. More specifically, these costs include distribution and administration costs along with management and depot fees. The net investment - after transaction costs have been charged - is denoted by $P_{0}^{i, \text { net }}$ and is given by the following relationship:

$$
P_{0}^{i, \text { net }}=P_{0}^{\text {gross }} \cdot\left(1-C_{0}^{i}\right)
$$

In addition, an investment time horizon (contract term) of $T$ years is considered. In Figure 1, the premium decomposition given in Equation (1) is illustrated.

\subsection{Dynamics of the underlying fund and input data}

For the dynamics of the underlying fund $A$ with values $A_{t}, t=0, \ldots, T$, we assume a geometric Brownian motion with constant drift $\mu_{A}$ and volatility $\sigma_{A}$. The stochastic process $A_{t}$ satisfies the following

\footnotetext{
${ }^{3}$ These assumptions are often used in the relevant literature, see, e.g., Gatzert and Kling (2007), Gatzert et al. (2012) and the primary sources cited therein.

${ }^{4}$ See Ibragimov et al. (2010) and Schluetter (2014).

${ }^{5}$ This investment form can be interpreted as the savings component of a unit-linked life insurance product without embedded investment guarantees.
} 


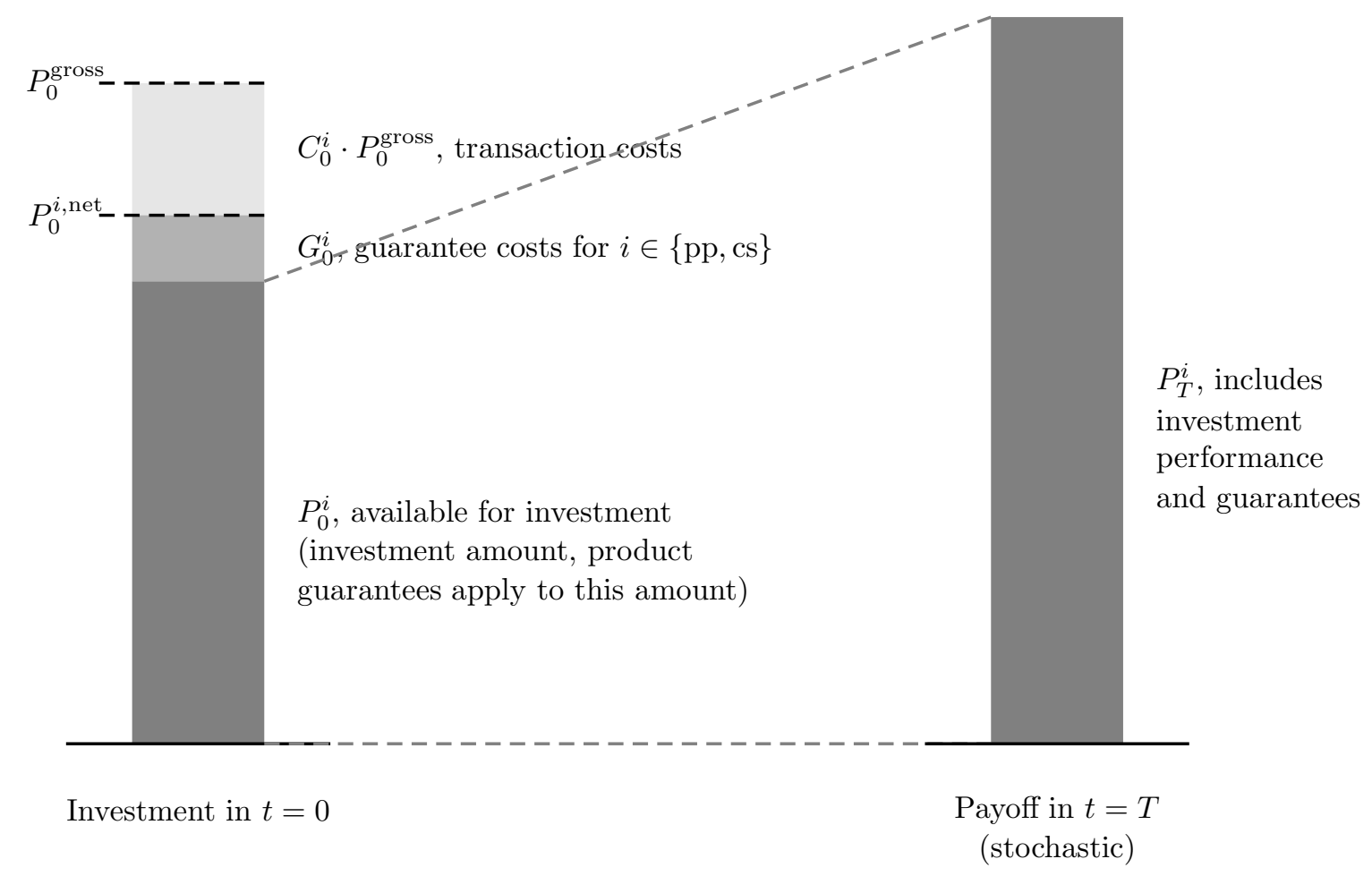

Figure 1: Illustration of the notations used in the model setup. $P_{0}^{\text {gross }}$ denotes the gross premium paid by the customer in time $t=0 ; P_{0}^{i, \text { net }}$ is the net premium in product $i$ after transaction $\operatorname{costs} C_{0}^{i} \cdot P_{0}^{\text {gross }} ; P_{0}^{i}$ is the amount available for investment in the chosen product after deduction of the guarantee costs $G_{0}^{i}$ if applicable. The final payoff $P_{T}^{i}$ in $t=T$ is based on the invested amount $P_{0}^{i}$, the investment returns and the granted guarantee.

stochastic differential equation:

$$
\mathrm{d} A_{t}=A_{t}\left(\mu_{A} \mathrm{~d} t+\sigma_{A} \mathrm{~d} W_{t}^{\mathbb{P}}\right) .
$$

Thereby, $W_{t}^{\mathbb{P}}$ (with $t=0, \ldots, T$ ) denotes a standard Brownian motion on a probability space $(\Omega, \Phi, \mathbb{P})$ and $\Phi_{t}, t=0, \ldots, T$, the filtration generated by the Brownian motion. The solution of the stochastic differential Equation (2) under the real-world measure $\mathbb{P}$ is given by

$$
A_{t}=A_{t-1} \cdot \exp \left[\mu_{A}-\sigma_{A} / 2+\sigma\left(W_{t}^{\mathbb{P}}-W_{t-1}^{\mathbb{P}}\right)\right]
$$

for $t=1, \ldots, T$, and initial asset value $A_{0}$ (see, e.g., Björk, 2004).

We derive the shares of various asset classes from the asset-allocation statistics of German life insurers (cf. Gesamtverband der Deutschen Versicherungswirtschaft, 2015, Exhibit 44) in the years 2010 to 2014. 
Thereby, the asset-allocation statistics are evaluated as follows: A set of five major asset classes labeled (1) to (5) are defined and reported in Table 1. The final column provides information about the share corresponding to the retained value for the parameterization used in our model.

$\left.\begin{array}{llc}\hline \text { (j) Asset Class } & \text { Historical share range } & \text { Retained share (in \%) } \\ \hline \text { (1) Government Bonds } & 87.1 \%(2010) \text { to } 88.5 \%(2014) & 88.0 \\ \text { (2) Stocks } & 5.5 \%(2010) \text { to } 5.8 \%(2014) & 5.5 \\ \text { (3) Real Estate } & 3.5 \%(2010) \text { to } 3.9 \%(2014) \\ \text { (4) Hedge Funds } & 3.9 \%(2010) \text { to } 1.9 \%(2014) \\ \text { (5) Money Market } & \text { in other shareholdings }\end{array}\right\}$

Table 1: Historical asset allocation statistics on five major selected asset classes in Germany (cf. Gesamtverband der Deutschen Versicherungswirtschaft, 2015, Exhibit 44) and the retained value for the parameterization used in the model.

To derive risk and return figures for the asset classes (1) to (5), we use representative indexes as introduced, for example, in Braun et al. (2015, Table 2). The annualized risk and return figures shown in Table 2 are based on monthly data and were derived from a 20.5-year time series from January 1995 to June 2015. In Table 2, we indicate for each index the (historical) annualized asset returns $\left(\right.$ mean $\mu_{j}$ and standard deviation $\left.\sigma_{j}, j=1, \ldots, 5\right)$. For the underlying fund $A$, we calculate the central moments of the yearly return distribution $\left(\mu_{A}, \sigma_{A}\right)$ by taking the correlation structure among the various asset classes into account. The correlation structure is derived from the annualized variance-covariance matrix reported in Table 3 .

\begin{tabular}{lclcc}
\hline$(j)$ Asset Class & Share (in \%) & Representing Index & $\mu_{j}$ & $\sigma_{j}$ \\
\hline (1) Government Bonds & 88.0 & REX Performance Index & $5.5 \%$ & $3.3 \%$ \\
(2) Stocks & 5.5 & EURO STOXX 50 Net Return & $9.1 \%$ & $18.9 \%$ \\
(3) Real Estate & 3.5 & Grundbesitz Europa Fund (TR) & $4.3 \%$ & $1.6 \%$ \\
(4) Hedge Funds & 1.5 & HFRI Fund Weighted Composite Index & $8.6 \%$ & $6.9 \%$ \\
(5) Money Market & 1.5 & 1 Month FIBOR/EURIBOR & $2.5 \%$ & $0.4 \%$ \\
\hline Underlying fund $A$ & 100.0 & (using variance-covariance matrix in Table 3) & $\mu_{A}=5.7 \%$ & $\sigma_{A}=2.8 \%$ \\
\hline
\end{tabular}

Table 2: Descriptive statistics of annualized asset returns from January 1995 to June 2015 (20.5-years time series).

Note: For the asset classes $j$, the used representing index, the mean $\mu_{j}$ and the standard deviation $\sigma_{j}$ of the annualized monthly index return time series (including coupons and dividends where applicable) are given. In the column "share (in \%)" the corresponding part in the underlying fund $A$ of each asset class $i$ is reported. The central moments of the yearly return distribution $\left(\mu_{A}, \sigma_{A}\right)$ are calculated taking into account the correlations between the various asset classes, also see Table 3. The Bloomberg tickers corresponding to the used indices used are (1) REXP Index, (2) SX5T Index, (3) GRNDBIN GR Equity, (4) HFRIFWI Index, and (5) FD0001M Index. 


\begin{tabular}{lrrrrr}
\hline$(j)$ Asset class & $(1)$ & $(2)$ & $(3)$ & $(4)$ & $(5)$ \\
\hline (1) Government Bonds & 0.0011 & -0.0017 & 0.0001 & -0.0005 & 0.0000 \\
(2) Stocks & -0.0017 & 0.0358 & -0.0002 & 0.0091 & 0.0000 \\
(3) Real Estate & 0.0001 & -0.0002 & 0.0003 & -0.0000 & 0.0000 \\
(4) Hedge Funds & -0.0005 & 0.0091 & -0.0000 & 0.0048 & -0.0000 \\
(5) Money Market & 0.0000 & -0.0001 & 0.0000 & -0.0000 & 0.0000 \\
\hline
\end{tabular}

Table 3: Annualized variance-covariance matrix of asset returns from 1995 to 2015 (see Table 2).

Given the input data from Tables 2 and 3, underlying fund $A$ yields $\mu_{A}=5.7 \%$ and $\sigma_{A}=2.8 \%$. These figures will be used as the parameterization of the reference setup provided in Table 4 .

\subsection{Different investment forms and risk-neutral valuation}

Let us assume a complete, frictionless, and continuous market. In this setting, there is a probability measure $\mathbb{Q}$ such that the discounted price process is a $\mathbb{Q}$-martingale (see, e.g., Harrison and Kreps, 1979). As a consequence of this transformation of measure the drift of the asset process changes from $\mu_{A}$ to the risk-free interest rate $r_{\mathrm{f}}$, and the evolution of the assets $A_{t}, t=1, \ldots, T$, is then given by

$$
A_{t}=A_{t-1} \cdot \exp \left[r_{\mathrm{f}}-\sigma_{A} / 2+\sigma\left(W_{t}^{\mathbb{Q}}-W_{t-1}^{\mathbb{Q}}\right)\right]
$$

with $\mathbb{Q}$-Brownian motion $W_{t}^{\mathbb{Q}}$ and an initial starting value $A_{0}$.

Let the contract value for each investment form $i$ (see Section 2.2) be given by $P_{t}^{i}, t=1, \ldots, T$. Below, we focus on the payoff distribution in $T$, that is $P_{T}^{i}$. For all investments $i$ considered, we require that the net present value $N P V$ of the investment must be zero; i.e., $N P V \stackrel{!}{=} 0$, that is, $P_{0} \stackrel{!}{=} \Pi_{0}$, where $\Pi_{0} \doteq E_{0}^{\mathbb{Q}}\left[P_{T}\right]=E^{\mathbb{Q}}\left[e^{-r_{\mathrm{f}} T} \cdot P_{T}\right]$. We call this form of pricing based on a risk-neutral valuation technique "fair" pricing throughout this paper.

\section{Life insurance product with point-to-point guarantee}

For a life insurance product with a point-to-point guarantee $(i=\mathrm{pp})$, we have the following relationships:

$$
\begin{aligned}
& P_{t}^{\mathrm{pp}}=P_{t-1}^{\mathrm{pp}} \cdot A_{t} / A_{t-1}, \quad \text { for } t \in\{1, \ldots, T-1\}, \\
& P_{T}^{\mathrm{pp}}=\max \left[P_{T-1}^{\mathrm{pp}} \cdot A_{T} / A_{T-1} ; P_{0}^{\mathrm{pp}} \cdot\left(1+g_{\mathrm{pp}}\right)\right] .
\end{aligned}
$$

Thereby, $g_{\mathrm{pp}}$ denotes the interest rate guarantee provided for the duration of the contract ( $T$ years), and $P_{0}^{\mathrm{pp}}$ stands for the initial effective savings premium. The final payoff $P_{T}^{\mathrm{pp}}$ is the greater of the value of the compounded returns of the underlying assets $\left(P_{0}^{\mathrm{pp}} \cdot A_{T} / A_{0}\right)$ and the guaranteed value of $P_{0}^{\mathrm{pp}} \cdot\left(1+g_{\mathrm{pp}}\right)$. 
Thus, $P_{0}^{\mathrm{pp}}$ is part of the available net investment $P_{0}^{\mathrm{pp} \text {, net }}$ and is determined such that

$$
P_{0}^{\mathrm{pp}, \text { net }} \stackrel{!}{=} E^{\mathbb{Q}}\left[e^{-r_{\mathrm{f}} T} \cdot P_{T}^{\mathrm{pp}}\right]
$$

The difference $G_{0}^{\mathrm{pp}}=P_{0}^{\mathrm{pp} \text {,net }}-P_{0}^{\mathrm{pp}}$ is the value of the point-to-point guarantee. The conceptual illustration in Figure 1 reflects the different variables introduced in this section.

\section{Life insurance product with cliquet-style guarantee and policyholder participation}

Next, we focus on a participating life insurance product $(i=\mathrm{cs})$ with a cliquet-style guarantee and a yearly interest rate guarantee $g_{\mathrm{cs}}$. Whenever yearly asset returns $\left(A_{t} / A_{t-1}-1\right)$ larger than $g_{\mathrm{cs}}$ occur, the policyholder will participate with a rate $\alpha_{\mathrm{cs}}$ in the insurer's profits. In formal terms, we set

$$
P_{t}^{\mathrm{cs}}=P_{t-1}^{\mathrm{cs}} \cdot\left(1+\max \left[g_{\mathrm{cs}}, \alpha_{\mathrm{cs}} \cdot\left(A_{t} / A_{t-1}-1\right)\right]\right), \quad \text { for } t \in\{1, \ldots, T\}
$$

where the initial effective savings premium $P_{0}^{\mathrm{cs}}$ (part of the investment $P_{0}^{\mathrm{cs}, \text { net }}$ ) is determined such that

$$
P_{0}^{\mathrm{cs}, \mathrm{net}} \stackrel{!}{=} E^{\mathbb{Q}}\left[e^{-r_{\mathrm{f}} T} \cdot P_{T}^{\mathrm{cs}}\right]
$$

\section{Mutual investment fund}

In the case of a direct investment $(i=\mathrm{fi})$ in the underlying fund without any investment guarantees, we have

$$
P_{T}^{\mathrm{fi}}=P_{0} \cdot \prod_{t=1}^{T} A_{t} / A_{t-1}=P_{0}^{\mathrm{fi}, \mathrm{net}} \cdot A_{T} / A_{0} .
$$

\section{Risk-free investment}

For the risk-free investment $\left(i=r_{\mathrm{f}}\right)$ the final payoff can be written as

$$
P_{T}^{r_{\mathrm{f}}}=P_{0}^{r_{\mathrm{f}}, \text { net }} \cdot e^{r_{\mathrm{f}} T}
$$

\subsection{Utility measurement}

We suppose that the customers investing in one of the products use a utility function to value the terminal payoff, i.e., the possible investment outcomes. For this reason, we introduce two utility measures. First, we use the mean-variance expected utility based on the mean and the variance of the terminal payoff $P_{T}^{i}$ of the contract. This is given by

$$
E U_{1}\left(P_{T}^{i}\right)=E\left[P_{T}^{i}\right]-\frac{a}{2} \sigma^{2}\left[P_{T}^{i}\right]
$$

where $a>0$ denotes the risk aversion parameter.

Second, we compare the results found through the formula in (12) with those obtained by applying a 
power (isoelastic) utility function given by

$$
U_{2}(w)= \begin{cases}\frac{w^{1-\rho}-1}{1-\rho}, & \text { if } \rho>0, \rho \neq 1 \\ \ln (w), & \text { if } \rho=1\end{cases}
$$

where $w$ is the wealth and $\rho$ is the Arrow-Pratt constant coefficient of relative risk aversion. In the case of Equation (13), decision making is unaffected by scale. The policyholder's increasing risk aversion is modeled through an increase in the coefficient $\rho$.

The corresponding expected utility of the payoff $P_{T}^{i}$ is calculated as follows:

$$
E U_{2}\left(P_{T}^{i}\right)=E\left[U_{2}\left(P_{T}^{i}\right)\right]
$$

\section{Numerical Simulation and Results}

To derive results and compare payoffs from the different products in our model setup, we use numerical simulations. We evaluate the investment payoffs using Monte Carlo simulation with 100000 simulation runs for the assets performance. The used parameters are described below and summarized in Table 4 .

The products underlying asset performance follows the figures presented in Table 2 . We set the riskfree rate of return $r_{\mathrm{f}}$ equal to $2 \%$ in the reference setup (this return is $0.5 \%$ below the historical 1-month money market rate of 2.5\%). There are no costs assumed when investing in the risk-free asset. For the product guarantees, we set $g_{\mathrm{pp}}=(1+1.25 \%)^{T}-1$, which corresponds to a point-to-point return guarantee of $1.25 \%$ over $T$ years on the initial savings amount. With respect to the life insurance product with a cliquet-style guarantee, we consider $g_{\mathrm{cs}}=1.25 \%$ (close to the annual guarantee of the point-to-point guarantee in the first product) and set the yearly profit participation $\alpha=90 \%$. These values (upper bound for the yearly guarantee, lower bound for the profit participation) correspond to the 2015 in-force reference values in Germany. For the rest of the contract parameters, we set the initial gross investment $P_{0}^{\text {gross }}$ to 1 . Thus, we can interpret all of the results per unit of gross investment. For the contract term, we choose $T=10$ years.

\subsection{Reference case without transaction costs}

We first consider the case without transaction costs. In this setting, the transaction cost ratio is set to zero, i.e., $C_{0}^{i}=0$. The net investment $P_{0}^{i, \text { net }}$ is equal to the gross investment amount of the investor $\left(P_{0}^{i, \text { net }}=\right.$ $\left.P_{0}^{\text {gross }}\right)$. The characteristics of the payoff distribution in $T$ in the four investment forms considered are reported in Table 5 . The mean value $E\left[P_{T}^{i}\right]$, standard deviation $\sigma\left[P_{T}^{i}\right]$, and skewness $\gamma\left[P_{T}^{i}\right]$ for the terminal distributions are given. Furthermore, for the reference situation considered, we report the value of the guarantee $G_{0}^{i}$ in both life insurance products.

Given the parameterization of the reference setup as defined in Table 4, we note that the two life insurance and the fund investments yield mean payoffs above the risk-free payoff. This is not surprising given the available risky asset allocation, which leads to high annual returns. However, the actual 


\begin{tabular}{|c|c|c|}
\hline Parameter & Variable & Value \\
\hline \multicolumn{3}{|l|}{ Investment performance } \\
\hline Expected return & $\mu_{A}$ & $5.7 \%$ \\
\hline Standard deviation of return & $\sigma_{A}$ & $2.8 \%$ \\
\hline Risk-free rate of return & $r_{\mathrm{f}}$ & $2 \%$ \\
\hline Costs for the risk-free investment & $C_{0}^{r_{\mathrm{f}}}$ & $0 \%$ \\
\hline \multicolumn{3}{|l|}{ Product guarantees } \\
\hline Point-to-point interest rate guarantee (in $T$ ) & $g_{\mathrm{pp}}$ & $(1+1.25 \%)^{T}-1$ \\
\hline Cliquet-style interest rate guarantee (yearly) & $g_{\mathrm{cs}}$ & $1.25 \%$ \\
\hline Cliquet-style profit participation (each year) & $\alpha$ & $90 \%$ \\
\hline \multicolumn{3}{|l|}{ Further contract parameters } \\
\hline Gross investment volume (C.U.) & $P_{0}^{\text {gross }}$ & 1.0 \\
\hline Contract term (years) & $T$ & 10 \\
\hline
\end{tabular}

Table 4: Summary of the input parameters for the reference setup.

\begin{tabular}{lccccc}
\hline Product & & $\begin{array}{c}\text { Life insurance } \\
\text { pt.-to-pt. guar. } \\
i=\mathrm{pp}\end{array}$ & $\begin{array}{c}\text { Life insurance } \\
\text { cliquet-st. guar. } \\
i=\mathrm{cs}\end{array}$ & $\begin{array}{c}\text { Fund } \\
\text { investment } \\
i=\mathrm{fi}\end{array}$ & $\begin{array}{c}\text { Risk-free } \\
\text { investment } \\
i=r_{\mathrm{f}}\end{array}$ \\
\hline Mean & $E\left[P_{T}^{i}\right]$ & 1.752 & 1.594 & 1.768 & 1.221 \\
Std. deviation & $\sigma\left[P_{T}^{i}\right]$ & 0.156 & 0.122 & 0.157 & 0.000 \\
Skewness & $\gamma\left[P_{T}^{i}\right]$ & 0.251 & 0.300 & 0.251 & n.a. \\
\hline Value of guarantee & $G_{0}^{i}$ & 0.009 & 0.053 & n.a. & n.a. \\
\hline
\end{tabular}

Table 5: Characteristics of the distributions $P_{T}^{i}$ in $T$ for the payoffs from the life insurance products with a point-to-point guarantee $\left(P_{T}^{\mathrm{pp}}\right)$ and with a cliquet-style guarantee $\left(P_{T}^{\mathrm{cs}}\right)$, from the mutual investment fund $\left(P_{T}^{\mathrm{fi}}\right)$ and from the risk-free investment $\left(P_{T}^{r_{\mathrm{f}}}\right)$. The parameterization used in the evaluation of the products is reported in Table 4.

investment value $P_{0}^{i}$ must also be considered (after subtracting the guarantee value $G_{0}^{i}$ levied in the life insurance products). Indeed, we observe considerable differences between the investment forms. Given the guarantee costs involved in both insurance investments, the starting net value of the account after guarantee costs $P_{0}^{i}$ is much lower. Non-guaranteed asset returns and an interest rate guarantee cannot lead to the same average payoff as the fund investment terminating at 1.768 currency units. The guarantee costs in the product with the cliquet-style guarantee are particularly high (5.3\% of the invested 
premium), leading to a lower average payout in $T$ while limiting the uncertainty, which is confirmed by the low standard deviation value (0.122) compared with the other two risky investments (0.156 and 0.157).

To include the customer preferences in our discussion, we consider the mean-variance expected utility of the payoffs for the various forms of investment. The resulting expected utility $E U_{1}$ in the four investment possibilities is illustrated in Figure 2. In that figure, we report the $E U_{1}$ for various values of the risk aversion parameter $a \in[0 ; 50]$ (steps of 5 ). We observe that the risky investment opportunities yield higher levels of expected utility $E U_{1}$ than the risk-free (and costless) investment. Only at very high levels of risk aversion $a$ is the risk-free investment preferable to the other investments. Thus, from the viewpoint of the product providers, the high levels of expected utility $E U_{1}$ from the insurance and fund investments (for $a$ between 0 and $\sim 40$ ) leave room to charge transaction fees and reserves for model and parameter risk. This provides the basis for discussing the maximum admissible fees that can be charged by product providers. We will consider this question in the sequel.

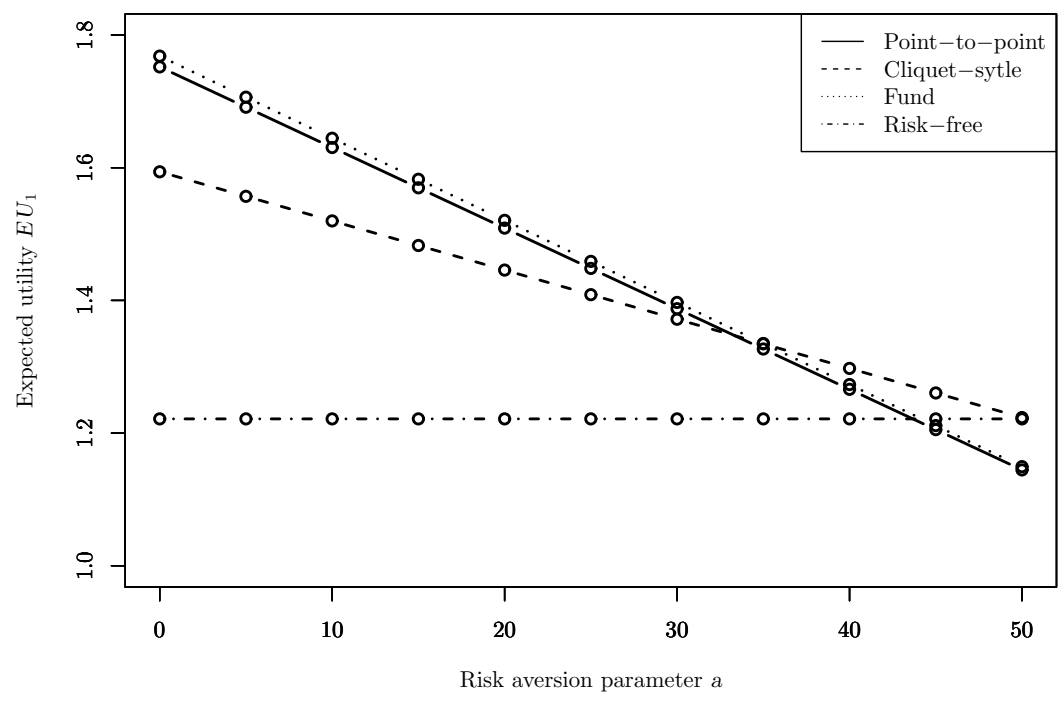

Figure 2: Illustration of the expected utility $E U_{1}$ of the payoffs from the life insurance products with a point-to-point guarantee $\left(P_{T}^{\mathrm{pp}}\right)$ and with a cliquet-style guarantee $\left(P_{T}^{\mathrm{cs}}\right)$, from the mutual investment fund $\left(P_{T}^{\mathrm{fi}}\right)$ and from the risk-free investment $\left(P_{T}^{r_{\mathrm{f}}}\right)$ for various values of the risk aversion parameter. The parameterization of the products is reported in Table 4.

\subsection{Case with transaction costs}

Our research objective is to determine the level of transaction costs for life insurance products that is acceptable from the customer's point of view. We express the level of transaction costs through the transaction cost ratio $C_{0}^{i}$ introduced in Section 2.2. The maximum acceptable transaction cost ratio $C_{0}^{i}$ is defined such that the expected utility from an investment form $i \in\{\mathrm{pp}, \mathrm{cs}$, fi $\}$ leads to an expected 
utility that is equal to the one from the risk-free investment. For the investor's valuation, we consider in this section the mean-variance expected utility $E U_{1}$ defined in (12). Formally, therefore, we aim to derive $C_{0}^{i} \geq 0$ from the condition

$$
E U_{j}\left(P_{T}^{i}\right)=E U_{j}\left(P_{T}^{r_{\mathrm{f}}}\right), \quad j=1,2
$$

Equation (15) indicates that we seek the maximum amount of transaction costs that can be charged by providers such that the expected utility $E U_{j}$ (here: $j=1$ ) is equal to the one of the costless risk-free investment. ${ }^{6}$

Using $E U_{1}$, we consider a range of values in the interval $a \in[0 ; 50]$ for the risk aversion parameter. Numerical results for the different investment forms $i$, and the various values of the risk aversion parameter are reported in Table 6 . We report the acceptable value of transaction costs $C_{0}^{i}$ in the three investment forms $i=\mathrm{pp}$, cs, fi, which fulfill Equation (15) for $j=1$. Recall that $C_{0}^{i}$ represents the amount of transaction costs as a percentage of the investment amount $P_{0}^{\text {gross }}$. In each investment form and for the various values of the risk aversion parameter, we also report the amount of the remaining net investment after transaction costs $P_{0}^{i, \text { net }}$ and the amount actually invested $P_{0}^{i}$ (after guarantee costs).

Certainly, the values obtained for $C_{0}^{i}$ strongly depend on the value of the risk aversion parameter. For $a=0$ (risk-neutrality), transaction costs can be as high as $30.9 \%$ of the gross investment amount until the expected utility from investment in the mutual fund falls to the expected utility from the risk-free investment. In the life insurance investment, this value is $30.2 \%$ for the product with a point-to-point guarantee and $23.1 \%$ for the product with a cliquet-style guarantee. In the case of the risk aversion parameter $a=30$, both values decrease to $15.2 \%$ and $12.6 \%$ for the investment forms pp and cs. In the case in which the risk aversion is much higher (e.g., $a=45$ and $a=50$ ), the expected utility from two investment forms (pp and fi) is already lower in the case without transaction costs so that Condition (15) cannot be fulfilled with $C_{0}^{i} \geq 0$.

\subsection{Discussion and sensitivity analyses}

Below, we discuss our results and compare the admissible costs with costs paid in practice. Furthermore, we discuss both the use of the second utility function and the relevance of rates of return and product guarantees in our model.

\section{Results obtained and comparison with industry practice}

In the first analysis reported above, different values of risk aversion parameter a lead to significantly different possible values for the maximum admissible amount of transaction costs. Values, in terms of the gross investment, range from $0 \%$ (highly risk-averse individuals) up to $30 \%$ (risk-neutral investors). Below, it is interesting to relate these values to the total product costs typically paid in practice.

\footnotetext{
${ }^{6}$ For high values of risk aversion parameter $a$, the expected utility of the risky investments may be lower than the expected utility from the risk-free investments that are already included in the case without costs (see Section 3.1 and Figure 2). In such a case, no positive value for $C_{0}^{i}$ can be derived. We will denote these cases with "n.a.", the abbreviation for "not applicable", in the reporting of our results, cf. Table 6.
} 


\begin{tabular}{|c|c|c|c|c|c|c|c|c|c|c|c|}
\hline Risk aversion $a$ & 0 & 5 & 10 & 15 & 20 & 25 & 30 & 35 & 40 & 45 & 50 \\
\hline \multicolumn{12}{|c|}{ Life insurance product with point-to-point guarantee $(i=\mathrm{pp})$} \\
\hline$P_{0}^{\text {gross }}$ & 1.000 & 1.000 & 1.000 & 1.000 & 1.000 & 1.000 & 1.000 & 1.000 & 1.000 & n.a. & n.a. \\
\hline$C_{0}^{\mathrm{pp}}\left(\% P_{0}^{\text {gross }}\right)$ & 30.2 & 28.4 & 26.4 & 24.2 & 21.7 & 18.7 & 15.2 & 11.0 & 5.4 & n.a. & n.a. \\
\hline$P_{0}^{\mathrm{pp}, \text { net }}$ & 0.698 & 0.716 & 0.736 & 0.758 & 0.783 & 0.813 & 0.848 & 0.890 & 0.946 & n.a. & n.a. \\
\hline$G_{0}^{\mathrm{pp}}\left(\% P_{0}^{\mathrm{gross}}\right)$ & 0.9 & 0.9 & 0.9 & 0.9 & 0.9 & 0.9 & 0.9 & 0.9 & 0.9 & n.a. & n.a. \\
\hline$P_{0}^{\mathrm{pp}}$ & 0.692 & 0.709 & 0.729 & 0.751 & 0.776 & 0.805 & 0.840 & 0.882 & 0.938 & 0.991 & 0.991 \\
\hline \multicolumn{12}{|c|}{ Life insurance product with cliquet-style guarantee $(i=\mathrm{cs})$} \\
\hline$P_{0}^{\text {gross }}$ & 1.000 & 1.000 & 1.000 & 1.000 & 1.000 & 1.000 & 1.000 & 1.000 & 1.000 & 1.000 & 1.000 \\
\hline$C_{0}^{\mathrm{cs}}\left(\% P_{0}^{\mathrm{gross}}\right)$ & 23.1 & 21.7 & 20.2 & 18.6 & 16.8 & 14.8 & 12.6 & 10.1 & 7.3 & 4.1 & 0.2 \\
\hline$P_{0}^{\mathrm{cs}, \mathrm{net}}$ & 0.769 & 0.783 & 0.798 & 0.814 & 0.832 & 0.852 & 0.874 & 0.899 & 0.927 & 0.959 & 0.998 \\
\hline$G_{0}^{\mathrm{cs}}\left(\% P_{0}^{\mathrm{gross}}\right)$ & 5.3 & 5.3 & 5.3 & 5.3 & 5.3 & 5.3 & 5.3 & 5.3 & 5.3 & 5.3 & 5.3 \\
\hline$P_{0}^{\mathrm{cs}}$ & 0.716 & 0.741 & 0.755 & 0.771 & 0.788 & 0.807 & 0.827 & 0.851 & 0.877 & 0.908 & 0.944 \\
\hline \multicolumn{12}{|c|}{ Mutual investment fund $(i=\mathrm{fi})$} \\
\hline$P_{0}^{\text {gross }}$ & 1.000 & 1.000 & 1.000 & 1.000 & 1.000 & 1.000 & 1.000 & 1.000 & 1.000 & n.a. & n.a. \\
\hline$C_{0}^{\mathrm{fi}}\left(\% P_{0}^{\text {gross }}\right)$ & 30.9 & 29.2 & 27.2 & 25.0 & 22.5 & 19.6 & 16.2 & 11.9 & 6.4 & n.a. & n.a. \\
\hline$P_{0}^{\mathrm{fi}}=P_{0}^{\mathrm{fi}, \mathrm{net}}$ & 0.691 & 0.708 & 0.728 & 0.750 & 0.775 & 0.804 & 0.838 & 0.881 & 0.936 & n.a. & n.a. \\
\hline
\end{tabular}

Table 6: The transaction cost levels $C_{0}^{i}$ such that $E U_{1}\left(P_{T}^{i}\right)=E U_{1}\left(P_{T}^{r_{\mathrm{f}}}\right)$ and the corresponding effective investment amounts are reported for different values of the risk aversion $a$ between $a=0$ and $a=50$ in the expected utility $E U_{1}$ for the considered investments $i=$ pp, cs, fi. Abbreviation: n.a. $=$ not applicable, see Footnote 6.

The analysis of costs in investment and insurance products is a topic of interest to consumer protection organizations and critical newspaper articles. When reviewing such publications, we find that in Germany, Austria and Switzerland, transaction costs (including sales provisions in life insurance products) can reach double-digit percentage values depending on the product. According to a recent analysis by Ökotest, a leading German consumer magazine, cost ratios (i.e., the costs over the premiums) average $20 \%$. The range of values for the costs obtained within our model reflect values found in practice; with that, our model can serve as a starting point for further analysis in academics and by practitioners when designing new products for customers.

\section{Utility function}

Choosing the utility function and defining the value of the risk aversion parameter for the average investor or insurance consumer is a difficult (if not impossible) task. On the one hand, in the analysis presented 
in Section 3.2 (see Table 6), we have chosen a range of values for the risk aversion parameter in the expected utility $E U_{1}$ defined through Equation (12). On the other hand, we want to report the outcome of the same analysis, i.e., calculating the maximum admissible transaction costs in the different contracts, when considering the utility function $U_{2}$ defined in Equation (13) and calculating the expected utility $E U_{2}$ through Equation (14). For the Arrow-Pratt constant coefficient of relative risk aversion $\rho$ taking values in $[2 ; 12]$, we report the expected utility $E U_{2}$ in the case without transaction costs in Figure 3 (to be compared with Figure 2).

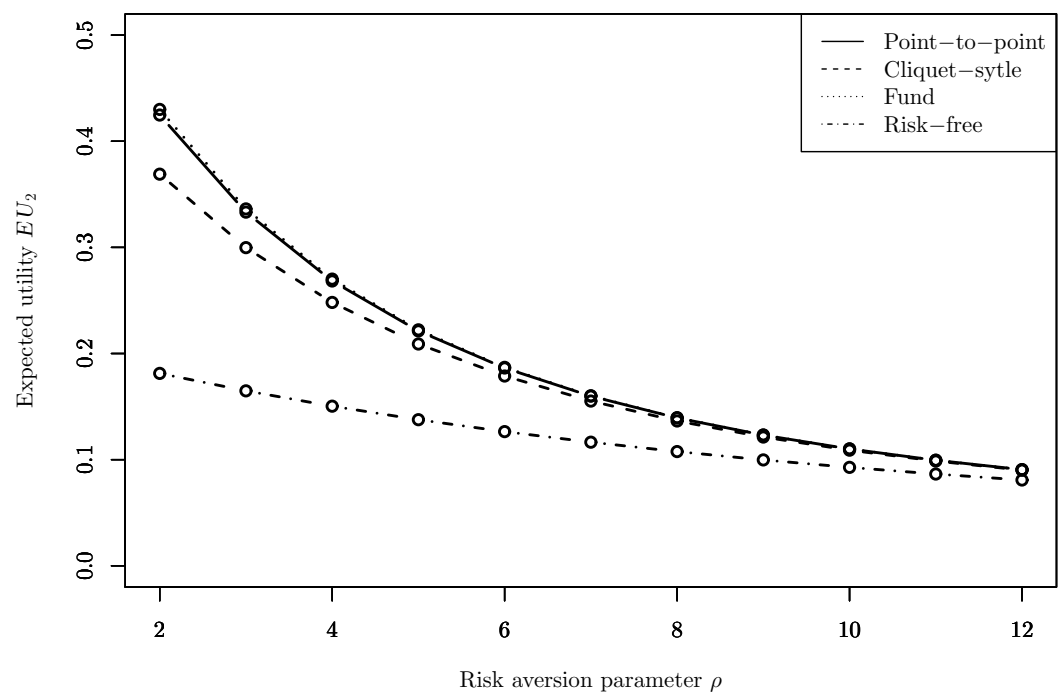

Figure 3: Illustration of the expected utility $E U_{2}$ of the payoffs from the life insurance products with a point-to-point guarantee $\left(P_{T}^{\mathrm{pp}}\right)$ and with a cliquet-style guarantee $\left(P_{T}^{\mathrm{cs}}\right)$, from the direct fund investment $\left(P_{T}^{\mathrm{fi}}\right)$ and from the risk-free investment $\left(P_{T}^{r_{\mathrm{f}}}\right)$ for various values of the risk aversion parameter. The parameterization of the products is reported in Table 4.

Furthermore, for the various values of $\rho$, we calculate the admissible transaction costs in the various investments and report the results in Table 7. When considering the results obtained when applying $E U_{2}$ in the calculation for the transaction costs, we see that the cost can comprise between $26.8 \%$ and $29.6 \%$ (for $\rho$ between 12 and 2) in the life insurance product with a point-to-point guarantee, and $20.5 \%$ to $22.7 \%$ in the product with a cliquet-style guarantee. These values correspond more to the upper range of the values obtained from the analysis using $E U_{1}$ (cf. Table 6). In the mutual investment, costs $C_{0}^{i}$ can be between $27.5 \%$ and $30.4 \%$ to keep the investment (utility-wise) as good as the risk-free investment. The results can also be interpreted in different way: Under the given conditions and for the case without transactions costs, risky investments are clearly preferred by the investors focused in this paper. In addition and in almost any case, an investment in the mutual funds is preferred. Hence, the willingness to pay for an embedded investment guarantee is in general not enough to cover the "fair" options price (based on risk-neutral valuation). This effect will even be more severe when taking into account that 
providers of investment guarantees may need to charge more for the embedded option than just the fair price (e.g., because of model and parameter risk) and transactions costs in guarantee products are higher compared to the ones included in mutual funds.

\begin{tabular}{|c|c|c|c|c|c|c|c|c|c|c|c|}
\hline Risk aversion $\rho$ & 2 & 3 & 4 & 5 & 6 & 7 & 8 & 9 & 10 & 11 & 12 \\
\hline \multicolumn{12}{|c|}{ Life insurance product with point-to-point guarantee $(i=\mathrm{pp})$} \\
\hline$P_{0}^{\text {gross }}$ & 1.000 & 1.000 & 1.000 & 1.000 & 1.000 & 1.000 & 1.000 & 1.000 & 1.000 & 1.000 & 1.000 \\
\hline$C_{0}^{\mathrm{pp}}\left(\% P_{0}^{\mathrm{gross}}\right)$ & 29.6 & 29.3 & 29.1 & 28.8 & 28.5 & 28.2 & 27.9 & 27.6 & 27.3 & 27.1 & 26.8 \\
\hline$P_{0}^{\mathrm{pp}, \text { net }}$ & 0.704 & 0.707 & 0.709 & 0.712 & 0.715 & 0.718 & 0.721 & 0.724 & 0.727 & 0.729 & 0.732 \\
\hline$G_{0}^{\mathrm{pp}}\left(\% P_{0}^{\mathrm{gross}}\right)$ & 0.9 & 0.9 & 0.9 & 0.9 & 0.9 & 0.9 & 0.9 & 0.9 & 0.9 & 0.9 & 0.9 \\
\hline$P_{0}^{\mathrm{pp}}$ & 0.697 & 0.700 & 0.703 & 0.706 & 0.709 & 0.711 & 0.714 & 0.717 & 0.720 & 0.723 & 0.726 \\
\hline \multicolumn{12}{|c|}{ Life insurance product with cliquet-style guarantee $(i=\mathrm{cs})$} \\
\hline$P_{0}^{\text {gross }}$ & 1.000 & 1.000 & 1.000 & 1.000 & 1.000 & 1.000 & 1.000 & 1.000 & 1.000 & 1.000 & 1.000 \\
\hline$C_{0}^{\mathrm{cs}}\left(\% P_{0}^{\mathrm{gross}}\right)$ & 22.7 & 22.5 & 22.3 & 22.0 & 21.8 & 21.6 & 21.4 & 21.2 & 20.9 & 20.7 & 20.5 \\
\hline$P_{0}^{\mathrm{cs}, \text { net }}$ & 0.773 & 0.775 & 0.777 & 0.780 & 0.782 & 0.784 & 0.786 & 0.788 & 0.791 & 0.793 & 0.795 \\
\hline$G_{0}^{\mathrm{cs}}\left(\% P_{0}^{\mathrm{gross}}\right)$ & 5.3 & 5.3 & 5.3 & 5.3 & 5.3 & 5.3 & 5.3 & 5.3 & 5.3 & 5.3 & 5.3 \\
\hline$P_{0}^{\mathrm{cs}}$ & 0.732 & 0.734 & 0.736 & 0.738 & 0.740 & 0.742 & 0.744 & 0.746 & 0.748 & 0.750 & 0.753 \\
\hline \multicolumn{12}{|c|}{ Mutual investment fund $(i=\mathrm{fi})$} \\
\hline$P_{0}^{\text {gross }}$ & 1.000 & 1.000 & 1.000 & 1.000 & 1.000 & 1.000 & 1.000 & 1.000 & 1.000 & 1.000 & 1.000 \\
\hline$C_{0}^{\mathrm{fi}}\left(\% P_{0}^{\text {gross }}\right)$ & 30.4 & 30.1 & 29.8 & 29.5 & 29.3 & 29.0 & 28.7 & 28.4 & 28.1 & 27.8 & 27.5 \\
\hline$P_{0}^{\mathrm{fi}}=P_{0}^{\mathrm{fi}, \mathrm{net}}$ & 0.696 & 0.699 & 0.702 & 0.705 & 0.707 & 0.710 & 0.713 & 0.716 & 0.719 & 0.722 & 0.725 \\
\hline
\end{tabular}

Table 7: The transaction cost levels $C_{0}^{i}$ such that $E U_{2}\left(P_{T}^{i}\right)=E U_{2}\left(P_{T}^{r_{\mathrm{f}}}\right)$ and the corresponding effective investment amounts are reported for different values of the risk aversion $\rho$ between $\rho=0$ and $\rho=40$ in the expected utility $E U_{2}$ for the considered investments $i=\mathrm{pp}$, cs, fi.

Finally, we note that in our analysis, one individual's investment (a life insurance product or mutual fund investment) is considered in an isolated way. However, other income sources - more precisely: the individual's stochastic basis income - may be relevant for an optimal decision. In particular, the correlation between the investment under scrutiny and the individual's stochastic basis can influence the result.

\section{Rates of return and product guarantees}

In our modeling, we consider a single reference setting for the interest rates and the setup of the life insurance products' guarantees. In practice, variations in the rate of return of the risk-free interest (e.g., decreasing from $3 \%$ to $2 \%$ and lower as has recently been observed in many European countries) and the 
volatility of the underlying investment will influence the cost of the guarantees and impact the terminal payoff. Additionally, in our model, if the risk-free interest rate $r_{\mathrm{f}}$ decreases, for a given (unchanged) guaranteed interest $g_{\mathrm{pp}}$ or $g_{\mathrm{cs}}$, the possible transaction costs obtained may be higher (very attractive high guarantee against a low return risk-free investment). Further research could create a more detailed model of the interactions among risky investment performance, risk-free interest rate models and product guarantees.

\section{Conclusion}

In this paper, we compare the savings part of two life insurance products with a mutual fund and a riskfree investment. The two life insurance products differ in respect to the embedded options: one product contains a point-to-point investment guarantee, the other one is a participating contract with an included cliquet-style put option. The portfolio structure of the underlying is the same for the mutual fund and the two life insurance products and is calibrated using empirical data. In a first step, the financial performance of the different saving opportunities under different assumptions of the utility measurement of the investor is studied. In a second step, we calculate the level of transactions costs that are allowed in the different products to make all investment opportunities equally rewarding from the investor's point of view.

The level of transactions costs strongly depends on the value of the risk aversion parameter. For a risk-neutral policyholder and the parameters and modeling assumptions used in our simulation study, transactions costs can amount for up to $30.2 \%$ (23.1\%) of the gross investment amount until the expected utility from the life insurance product's payoff with point-to-point guarantee (cliquet-style guarantee) reduces to the expected utility from the risk-free investment. For a risk-averse policyholder with a risk aversion parameter of $a=30$, these values reduce to $15.2 \%$ (in the case of a point-to-point guarantee) and $12.6 \%$ (for the cliquet-style guarantee) respectively. Comparing these results with transactions costs common in the market - typical values are around $20 \%$ - it can be argued that insurance companies need to be careful with the level of transactions costs they pass to their customers in order to provide attractive payoff distributions.

The results laid down in the paper need to be interpreted in respect of the following aspects: The numerical findings will certainly differ when using other assumptions regarding the (stochastic) behavior of assets, interest rates, and investor's preferences. In addition, the investor may hold some stochastic basic income beside the investment opportunities in focus and hence the results will vary if other risk sources are taken into account. However, in order to account for these effects, detailed assumptions for the stochastic basis income of one particular investor need to be taken and the covariance structure between the different investment products and the stochastic basis income will become crucial. Finally, it needs to be mentioned that the stochastic investment opportunities observed in this paper contain the same asset allocation. Even though this procedure allows comparing the different investment forms, the used asset allocation is in general not optimal for a particular investor with some given utility function and a specific degree of risk aversion. Hence, investors could improve their utility by looking for optimal asset allocation structures in different products depending on their individual preferences. 


\section{References}

Bacinello, A., 2003, Fair Valuation of a Guaranteed Life Insurance Participating Contract Embedding a Surrender Option, The Journal of Risk and Insurance, 70(3):461-487.

Ballotta, L., S. Haberman, and N. Wang, 2006, Guarantees in With-Profit and Unitized With-Profit Life Insurance Contracts: Fair Valuation Problem in Presence of the Default Option, The Journal of Risk and Insurance, 73(1):97-121.

Berketi, A. K., 1999, Insolvency Risk and its Impact on the Policyholders Investment Choices: A MeanVariance Approach for Participating Life Insurance Business in UK, Insurance: Mathematics and Economics, 25(3):349-372.

Björk, T., 2004, Arbitrage Theory in Continuous Time. Oxford University Press, New York.

Braun, A., H. Schmeiser, and F. Schreiber, 2015, Portfolio Optimization Under Solvency II: Implicit Constraints Imposed by the Market Risk Standard Formula, The Journal of Risk and Insurance, (forthcoming).

Briys, E. and F. de Varenne, 1997, On the Risk of Insurance Liabilities: Debunking Some Common Pitfalls, The Journal of Risk and Insurance, 64(4):673-694.

Doherty, N. and A. Richter, 2002, Moral Hazard, Basis Risk, and Gap Insurance, The Journal of Risk and Insurance, 69(1):9-24.

Doherty, N. and S. Tinic, 1981, Reinsurance under Conditions of Capital Market Equilibrium: A Note, Journal of Finance, 36(4):949-953.

Donnelly, C., M. Guillén, and J. P. Nielsen, 2014, Bringing Cost Transparency to the Life Annuity Market, Insurance: Mathematics and Economics, 56:14-27.

Døskeland, T. M. and H. a. Nordahl, 2008, Optimal Pension Insurance Design, Journal of Banking and Finance, 32(3):382-392.

Ehrlich, I. and G. Becker, 1972, Market Insurance, Self-Insurance, and Self-Protection, The Journal of Political Economy, 80(4):623-648.

Eling, M. and S. Holder, 2013, The Value of Interest Rate Guarantees in Participating Life Insurance Contracts: Status Quo and Alternative Product Design, Insurance: Mathematics and Economics, 53(3):491-503.

Gatzert, N., 2008, Asset Management and Surplus Distribution Strategies in Life Insurance: An Examination with Respect to Risk Pricing and Risk Measurement, Insurance: Mathematics and Economics, 42(2):839-849.

Gatzert, N., I. Holzmüller, and H. Schmeiser, 2012, Creating Customer Value in Participating Life Insurance, The Journal of Risk and Insurance, 79(3):645-670. 
Gatzert, N. and A. Kling, 2007, Analysis of Participating Life Insurance Contracts: A Unification Approach, The Journal of Risk and Insurance, 74(3):547-570.

Gatzert, N. and H. Schmeiser, 2009, Pricing and Performance of Mutual Funds: Lookback versus Interest Rate Guarantees, The Journal of Risk, 11(4):31-49.

Gesamtverband der Deutschen Versicherungswirtschaft, 2015, Statistisches Taschenbuch der Versicherungswirtschaft 2015.

Grosen, A. and P. Jorgensen, 2002, Life Insurance Liabilities at Market Value: An Analysis of Insolvency Risk, Bonus Policy, and Regulatory Intervention Rules in a Barrier Option Framework, The Journal of Risk and Insurance, 69(1):63-91.

Guillén, M., S. F. Jarner, J. P. Nielsen, and A. M. Pérez-Marín, 2014, Risk-Adjusted Impact of Administrative Costs on the Distribution of Terminal Wealth for Long-Term Investment, Scientific World Journal, ID 521074.

Guillén, M., A. K. Konicz, J. P. Nielsen, and A. M. Pérez-Marín, 2012, Do Not Pay for a Danish interest guarantee. The law of the triple blow, Annals of Actuarial Science, 7(02):192-209.

Guillén, M., J. P. Nielsen, A. M. Pérez-Marín, and K. S. Petersen, 2013, Performance Measurement of Pension Strategies: a Case Study of Danish Life-Cycle Products, Scandinavian Actuarial Journal, 1:49-68.

Harrison, J. and D. Kreps, 1979, Martingales and Arbitrage in Multiperiod Securities Markets, Journal of Economic Theory, 20(3):381-408.

Ibragimov, R., D. Jaffee, and J. Walden, 2010, Pricing and Capital Allocation for Multiline Insurance Firms, The Journal of Risk and Insurance, 77(3):551-578.

Kronborg, M. T. and S. F. Jarner, 2015, Why You Should Care about Investment Costs: A Risk-Adjusted Utility Approach, Journal of Behavioral and Experimental Finance, 6:56-66.

Mayers, D. and C. Smith, 1983, The Interdependence of Individual Portfolio Decisions and the Demand for Insurance, Journal of Political Economy, 91(2):304-311.

Mayers, D. and C. W. Smith, 1982, On the Corporate Demand for Insurance, The Journal of Business, $55(2): 281$.

Raviv, A., 1979, The Design of an Optimal Insurance Policy, The American Economic Review, 69(1):8496.

Schluetter, S., 2014, Capital Requirements or Pricing Constraints? An Economic Analysis of Measures for Insurance Regulation, Journal of Risk Finance, 15(5):533-554.

Schmeiser, H. and J. Wagner, 2011, A Joint Valuation of Premium Payment and Surrender Options in Participating Life Insurance Contracts, Insurance: Mathematics and Economics, 49(3):580-596. 
Schmeiser, H. and Wagner, J. (2016), Journal of Risk Finance, Vol. 17 No. 3, pp. 277-294.

Schmeiser, H. and J. Wagner, 2015, A Proposal on How the Regulator Should Set Minimum Interest Rate Guarantees in Participating Life Insurance Contracts, The Journal of Risk and Insurance, 82(3):659686.

Swiss Re, 2014, The effect of the interest rate environment on Canadian insurers, Technical Report July 2014 .

Swiss Re, 2015, World insurance in 2014: back to life, sigma, No 4/2015.

Zemp, A., 2011, Risk Comparison of Different Bonus Distribution Approaches in Participating Life Insurance, Insurance: Mathematics and Economics, 49(2):249-264. 